\title{
Glomus Tumor of the Buttock
}

\author{
Safa Idoudi ${ }^{1}$, Aycha Arousse ${ }^{1}$, Lobna Boussofara ${ }^{1}$
}

1 Dermatology Department, Farhat Hached University Hospital, Sousse, Tunisia

Key words: glomus tumor, dermoscopy, dermatology, tumor

Citation: Idoudi S, Arousse A, Boussofara L. Glomus tumor of the buttock. Dermatol Pract Concept. 2019;9(4):318-319. DOI: https://doi. org/10.5826/dpc.0904a19

Accepted: July 16, 2019; Published: October 31, 2019

Copyright: @2019 Idoudi et al. This is an open-access article distributed under the terms of the Creative Commons Attribution License, which permits unrestricted use, distribution, and reproduction in any medium, provided the original author and source are credited.

Funding: None.

Competing interests: The authors have no conflicts of interest to disclose.

Authorship: All authors have contributed significantly to this publication.

Corresponding author: Lobna Boussofara, MD, Dermatology Department, Farhat Hached University Hospital, Ibn Jazzar Avenue, 4000 Sousse, Tunisia. Email: boussofara_1@yahoo.fr

\section{Introduction}

First defined in 1812 by Wood, glomus tumors were known as "painful subcutaneous tubercles." They commonly occur in middle-aged women and by the fifth decade in men. They are known as uncommon benign neuromyoarterial neoplasms that usually occur in the subungual region of the finger. Extradigital location of glomus tumor is rare [1]: The forearm has been reported as the most common extradigital location. Palm, wrist, and foot could also be affected. It generally appears as a solitary, small, pinkish tumor, or as multiple ones. We present a case of glomus tumor located on the buttock.

\section{Case Presentation}

A 65-year-old man with a history of myocardial infarction presented with a small, painful nodule of the left buttock of 15 years' duration. The patient reported intense pain at pressure and movement that had recently worsened, triggered by the slightest touch. Neither spontaneous pain nor cold sensitivity was reported. Examination revealed a well-defined, 7- $\times$ 7-mm, purple nodule on the upper external quadrant of the left buttock (Figure 1). Polarized non- contact dermoscopy (Figure 2A) showed a central purple color surrounded by a whitish area and an external brown pigmentation. The diagnosis of extradigital glomus tumor was suspected, and it was confirmed by histopathological analysis, which showed a proliferation of blood vessels surrounded by small, uniform cells with round or oval nuclei (glomus cells) (Figure 2B). The lesion was completely removed surgically.

\section{Conclusion}

The classic triad of symptoms of glomus tumor-pain, pinpoint tenderness, and cold hypersensitivity-is very suggestive, but it may be incomplete as shown in our patient, leading to misdiagnosis. While described in a few cases, dermoscopic features may provide additional clues to the diagnosis: The central purple color corresponds to the enlarged vessels within the neuromyoarterial glomus body. The external whitish area is related to the fibrous capsule of the tumor, while the external brown pigmentation might be explained by its long course [2]. Specific imaging techniques are recommended, even though MRI could provide more details of the lesion and its association with the adjacent structures. Confirmation relies always on histopathological 


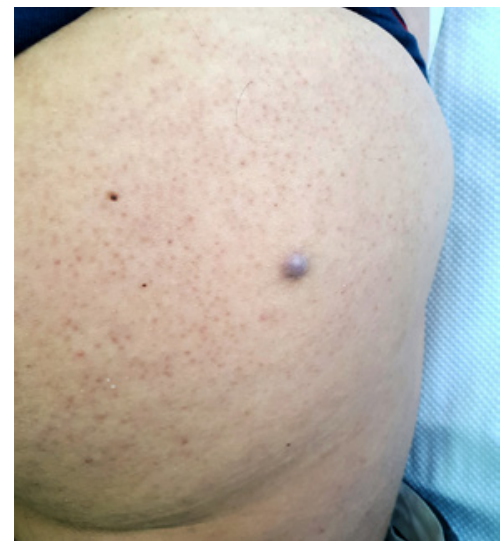

Figure 1. Purple nodule of the upper external quadrant of the left buttock. [Copyright: (2019 Idoudi et al.]

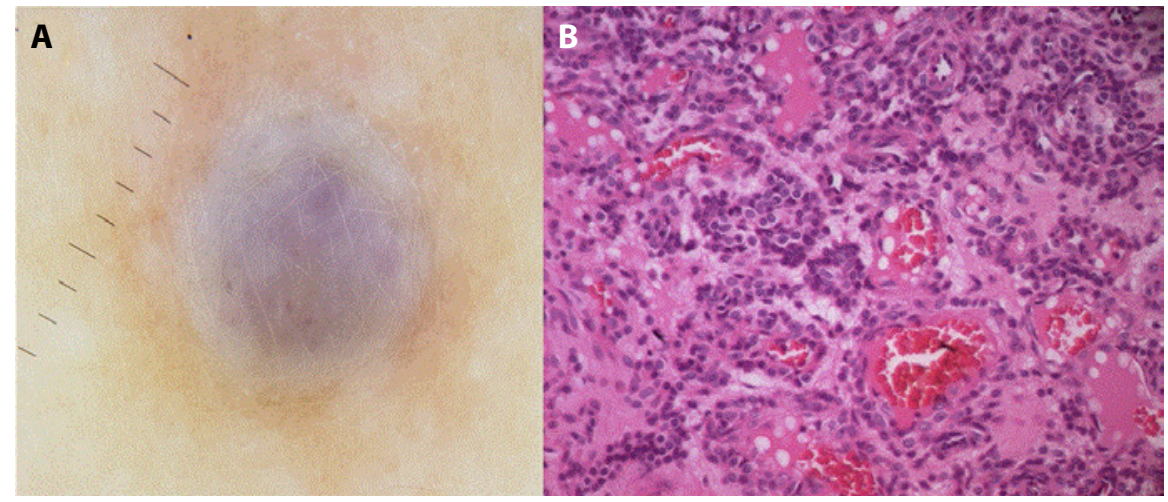

Figure 2. (A) Polarized noncontact dermoscopy showed a central purple color surrounded by a whitish area and an external brown pigmentation. (B) Histopathological analysis showed proliferation of blood vessels surrounded by small, uniform cells with round or oval nuclei (glomus cells). [Copyright: @2019 Idoudi et al.] findings showing an encapsulated fibrous tumor, with vascular spaces surrounded by glomus cells. Surgical excision remains the only therapeutic option that provides immediate pain relief. It consists of wide excision of the tumor to avoid its recurrence. At the time of the present report, the patient continued dermatological follow-up and no recurrence was noted.

\section{References}

1. Lee DW, Yang JH, Chang S, et al. Clinical and pathological characteristics of extradigital and digital glomus tumours: a retrospective comparative study. J Eur Acad Dermatol Venereol. 2011;25(12):1392-1397.

2. Oliveira A. Dermoscopy in the diagnosis of extradigital glomus tumors. Int J Dermatol. 2016;55(9):e506-e508. 